\title{
Measurement Index System Establishment of Public Sports Service of Urban-Rural Integration in Heilongjiang Province
}

\author{
Zheng Zhao ${ }^{1, \text { a }}$, Shufeng Liu ${ }^{1, b}$, Meng Zhao, c,*, Yuhang Wang ${ }^{2, d}$, Xingang \\ Wang ${ }^{1,}$, Xinghe Cui ${ }^{1, f}$ and Dapeng Zhou ${ }^{3, g}$ \\ ${ }^{1}$ Jiamusi University, Jiamusi 154007, China \\ ${ }^{2}$ Harbin College, Harbin 150086, China \\ ${ }^{3}$ Heilongjiang College of Technology, Jixi 158100, China \\ a'Zhaozhangyaqi1@163.com, bliushufeng0828@163.com, cjmszhaozheng@163.com, \\ dwangyuhang1978@sina.com, ewxg19750523@sina.com, ${ }^{\dagger}$ cxh1973@163.com, \\ gzhoudapeng16@163.com \\ *The corresponding author
}

Keywords: Public sports service; Urban-rural integration; Measurement index system

\begin{abstract}
This study obtains more accurate data by means of questionnaires, literature, field investigation, mathematical statistics methods. Using AHP method to determine the index system and variance decision method to determine the weights of indicators, the measurement index system of public sports service of urban-rural integration has been established. Through the discovery of bottlenecks and malpractice in the implementation process of public sports service of urban-rural integration, the implement process monitoring of public sports service of urban-rural integration have been realized.
\end{abstract}

\section{Introduction}

"No urban and rural differences" is an important indicator to measure the human social progress and social civilization [1], it is also the inevitable result of modern society development. In 2013, the GDP of Heilongjiang Province was 1.5 trillion Yuan, reached 39,350 Yuan per capita, the level of urbanization reached $58.8 \%$. Under such a macro-background, the capacity of public sports services in urban areas is much higher than that of rural areas, even no public sports are in rural areas. How to make the public sports have no difference between urban and rural areas, urban and rural residents enjoy public sports services fairly, the establishment of public sports service measurement index system of urban-rural integration is particularly significant.

Many experts and scholars opposed the theory of "integration of urban and rural". According to the three-stage theory of urban-rural relations of Marx and Engels, scholars considered that urban-rural integration is contrary to the current development guidelines of urban and rural areas of China. Moreover, researchers thought that the development direction of urban-rural integration and urbanization was completely different, so the integration of urban and rural areas as the adjustment of China's urban and rural development relations and guiding ideology was not feasible [2].

At the same time, the integration of urban and rural areas is the highest goal of human society development, urban and rural integration theory has been put forward is not suitable for the development strategy for China's current stage [3]. The questioned view is due to the one-side and narrow interpretation of urban-rural integration. The integration of urban and rural areas is an important part of China's national development strategy. The country will reintegrate all labor subjects and resources to improve the economic development model and efficiency to solve the long-standing problems of urban-rural differences [4-5]. 


\section{Measurement Index System Establishment of Public Sports Service of Urban-rural Integration}

The public sports service in urban and rural areas due to geographical differences, economic disparities, cultural differences and other factors exists differences for a long time. The establishment of scientific and rational measurement index system can guide the future of public sports services. So the gap accompanied by different geographical factors and different environmental factors will change.

Theoretical Support of Measurement Index System of Urban-rural Integration. For establishing the measurement index system of public sports service of Urban-Rural Integration, the core content is to choose the measurement indicators. Therefore, the city and township is the evaluation main body, the relationship between urban-rural areas must be firmly grasped, but the selection of core competitiveness indicators is difficult relative to other indicators. Many scholars do not have consistency about the choice of of urban-rural integration indicators, economic, social, cultural, infrastructure and other indicators are the main choices, these indicators provide guidance and reference for the scientific and systematic construction of public sports service index system, but also reflects the lack of public sports service of urban-rural integration evaluation system. In this paper, two quantitative methods are used to determine the weight of indicators, and avoiding strong subjective assumptions, thus the scientific characteristic of the study can be ensured.

Survey Objects and Research Methods. 20 experts engaged in social sports in Heilongjiang Province or similar scholars in this field were selected to guide the establishment of measurement index system of public sports service of urban-rural integration. The social status and background of experts are shown in Table 1.

Table 1 Statistics of social status and background of experts

\begin{tabular}{lcc}
\hline \multicolumn{1}{c}{ Occupation } & Number & Percentage / \% \\
\hline Leadership of Heilongjiang Province Sports Bureau & 4 & 20 \\
Staff of Heilongjiang Provincial Sports Bureau & 4 & 20 \\
Experts engaged in social sports research & 8 & 40 \\
Experts engaged in regional economic research & 4 & 20 \\
\hline
\end{tabular}

Questionnaires, literature, field investigation, mathematical statistics and other research methods have been adopted as the research methods. Research groups visited the Heilongjiang Provincial Sports General Administration, Harbin Municipal Sports Bureau, Jiamusi City Sports Bureau, the surrounding 10 township social sports instructor stations and 20 village-level morning exercise site and obtained lots of research information.

This study firmly grasps the three elements of measuring goals, measuring contents and measuring objects, makes full use of qualitative analysis and quantitative analysis, combines the theory of urban-rural integration, adopts the suggestions of experts and scholars, two questionnaire formats of close and open type have been designed. The Liker five scales of 3 pairs of second-level indicators and 17 pairs of third-level indicators have been set, the specific contents of indicators are in Table 2, after the test of the reliability and validity, two rounds of investigation of the experts have been conducted. 
Table 2 Specific contents of second-level and third-level indicators

\begin{tabular}{|c|c|c|}
\hline $\begin{array}{l}\text { Indicator } \\
\text { Type }\end{array}$ & $\begin{array}{c}\text { Second-level } \\
\text { Indicator } \\
\text { / B }\end{array}$ & $\begin{array}{l}\text { Third-level Indicator } \\
\qquad / \mathrm{C}\end{array}$ \\
\hline \multirow{17}{*}{$\begin{array}{c}\text { Indicator } \\
\text { System } \\
\text { Content } \\
\text { /A }\end{array}$} & \multirow{4}{*}{$\begin{array}{c}\text { Element } \\
\text { Integration } \\
\text { / B1 }\end{array}$} & Sports area ratio per capita of urban and rural residents / C1 \\
\hline & & Sports funding ratio per capita of urban and rural residents / C2 \\
\hline & & Social sports instructors ratio of per 1000 people of urban and rural residents / C3 \\
\hline & & Fitness project ratios of per thousand people of urban and rural residents / C4 \\
\hline & \multirow{7}{*}{$\begin{array}{c}\text { Management } \\
\text { Integration } \\
\text { / B2 }\end{array}$} & Public service managers ratio per 1000 people of urban and rural residents / C5 \\
\hline & & $\begin{array}{l}\text { Number of sports information Service Stations ratio per } 1000 \text { people of urban and } \\
\text { rural residents / C6 }\end{array}$ \\
\hline & & $\begin{array}{l}\text { Number ratio of Policies and Regulations on public sports services of urban and rural } \\
\text { residents / C7 }\end{array}$ \\
\hline & & $\begin{array}{l}\text { Number ratio of participate in fitness exchanges and learning of urban and rural } \\
\text { residents / C8 }\end{array}$ \\
\hline & & $\begin{array}{l}\text { Average times ratio of social sports instructors per week of urban and rural residents } \\
\text { / C9 }\end{array}$ \\
\hline & & Number ratio of sports lottery tickets of urban and rural residents / C10 \\
\hline & & $\begin{array}{l}\text { Number ratio of participating in fitness activities and competitions of urban and rural } \\
\text { residents / C11 }\end{array}$ \\
\hline & \multirow{6}{*}{$\begin{array}{l}\text { Development } \\
\text { level } \\
\text { integration } \\
\quad \text { / B3 }\end{array}$} & Number ratio of per 1000 sports population of urban and rural residents / C12 \\
\hline & & $\begin{array}{l}\text { Number ratio of sports fitness teams per } 1000 \text { people of urban and rural residents / } \\
\text { C13 }\end{array}$ \\
\hline & & Sports journals total sales ratio of urban and rural areas / C14 \\
\hline & & Ratio of urban and rural residents' physical fitness and health / C15 \\
\hline & & Ratio of sports population in urban and rural areas to the total population / C16 \\
\hline & & xpenditure Ratio Per \\
\hline
\end{tabular}

Measurement Index System Formation of Public Sports Service of Urban-rural Integration. First of all, through the questionnaire to establish second-level indicators of public sports service of urban-rural integration, the investigation time is set as 7 days for a cycle, adopting two rounds investigation. Then, through the questionnaire to establish third-level indicators, the survey time is still 7 days as a cycle, two investigation rounds. The start date of the first round of implementation was Nov. 14th. 2014; the second round start date was Dec. 05th. 2014.

The Likert Five Scale was designed to evaluate the initial index system. Two expert questionnaire survey showed that 20 experts scored for the second-level indicators and third-level indicators, if the score was $\geqslant 4$, it can be reserved; if the score was $<4$, it can be removed, the scores of 3 pairs second-level indicators B1, B2, and B3 were 4.6, 4.95 and 4.3, respectively, the scores were $\geqslant 4$, so reserved; the scores of 17 pairs of third-level indicators are in Table 3 , and twelve indicators can be reserved. After comprehensive analysis, expert scoring results had high degree of concentration and coordination, reflecting the consistency and stability of indicators, suggesting that indicators setting in line with the selection criteria, thus the screening work of indicators finished. 
Table 3 Statistical results of third-level indicators after two rounds of expert survey

\begin{tabular}{ccccccccccccccccccc}
\hline Round & $\mathrm{C} 1$ & $\mathrm{C} 2$ & $\mathrm{C} 3$ & $\mathrm{C} 4$ & $\mathrm{C} 5$ & $\mathrm{C} 6$ & $\mathrm{C} 7$ & $\mathrm{C} 8$ & $\mathrm{C} 9$ & $\mathrm{C} 10$ & $\mathrm{C} 11$ & $\mathrm{C} 12$ & $\mathrm{C} 13$ & $\mathrm{C} 14$ & $\mathrm{C} 15$ & $\mathrm{C} 16$ & $\mathrm{C} 17$ \\
\hline First & 4.3 & 4.6 & 4.9 & 4.5 & 3.1 & 2.7 & 5 & 5 & 5 & 3.8 & 5 & 4.1 & 4.4 & 4.1 & 4.3 & 3.3 & 4.2 \\
Second & 4.4 & 4.7 & 4.9 & 4.8 & 3.7 & 2.9 & 5 & 4.9 & 5 & 3.7 & 5 & 4.3 & 4.7 & 3.7 & 4.3 & 3.5 & 4.1 \\
Average & 4.35 & 4.65 & 4.9 & 4.65 & 3.4 & 2.8 & 5 & 4.95 & 5 & 3.75 & 5 & 4.2 & 4.55 & 3.9 & 4.3 & 3.4 & 4.15 \\
\hline
\end{tabular}

\section{Measurement Index System Judgment of Public Sports Service of Urban-rural Integration}

The analytic hierarchy method (AHP) method and the mean variance decision method were used to determine the weight of each indicator, and to highlight objectivity and avoid subjective assumptions.

Using AHP Method to Determine the Index Weights. AHP method is a scientific and accurate analysis method, which can quantify the qualitative problems and solve the practical problems. The key of this method is the creation of judgment matrix to deal with the multi-index decision problems. According to the actual survey data and expert advice, the judgment matrices for constructing the second-level index and the third-level index separately for this problem are shown in Table 4 and Table 5.

Table 4 Judgment matrices of second-level index

\begin{tabular}{cccc}
\hline $\mathrm{A}$ & $\mathrm{B} 1$ & $\mathrm{~B} 2$ & $\mathrm{~B} 3$ \\
\hline $\mathrm{B} 1$ & 1 & 0.93 & 1.07 \\
$\mathrm{~B} 2$ & 1.08 & 1 & 1.15 \\
$\mathrm{~B} 3$ & 0.93 & 0.87 & 1 \\
\hline
\end{tabular}

Table 5 Judgment matrices of third-level indicators

\begin{tabular}{ccccc}
\hline $\mathrm{B} 1$ & $\mathrm{C} 1$ & $\mathrm{C} 2$ & $\mathrm{C} 3$ & $\mathrm{C} 4$ \\
\hline $\mathrm{C} 1$ & 1 & 0.94 & 0.89 & 0.94 \\
$\mathrm{C} 2$ & 1.07 & 1 & 0.95 & 1 \\
$\mathrm{C} 3$ & 1.13 & 1.05 & 1 & 1.05 \\
$\mathrm{C} 4$ & 1.07 & 1 & 0.95 & 1 \\
\hline
\end{tabular}

\begin{tabular}{ccccc}
\hline B2 & C7 & C8 & C9 & C11 \\
\hline C7 & 1 & 1.01 & 1 & 1 \\
C8 & 0.99 & 1 & 0.99 & 0.99 \\
C9 & 1 & 1.01 & 1 & 1 \\
C11 & 1 & 1.01 & 1 & 1 \\
\hline
\end{tabular}

\begin{tabular}{ccccc}
\hline B3 & C12 & C13 & C15 & C17 \\
\hline C12 & 1 & 0.92 & 0.98 & 1.01 \\
C13 & 1.08 & 1 & 1.06 & 1.10 \\
C15 & 1.02 & 0.95 & 1 & 1.04 \\
$\mathrm{C} 17$ & 0.99 & 0.91 & 0.97 & 1 \\
\hline
\end{tabular}

It is proved that the above judgment matrices have good consistency. Using the specific algorithm of AHP, we get the unified weight of the second-level indicators:

The secondary indicators: $\mathrm{W} 2=(0.3321,0.3574,0.3105)$

The weight of the second-level indicators reflects the importance of the second-level indicators to the target layer.

The combined weights of the third-level indicators are: $\mathrm{W} 3=(0.1173,0.1253,0.1321,0.1253$, $0.0751,0.0744,0.0751,0.0751,0.0489,0.0530,0.0501$, and 0.0483 )

The combined weight of the three-level indicators reflects the importance of the third-level indicators on the target layer, the specific weight indicators are in Table 6.

Determination of the Index Weight by Using Mean Variance Analysis Method. The weights of multi-index decision-making problem can be calculated by means of mean square variance analysis method. The formula is as Eq.1: 


$$
s_{j}=\sqrt{\sum_{i}\left(x_{i j}-\overline{x_{j}}\right)^{2}}, w_{j}=\frac{s_{j}}{\sum_{i} s_{i}}, j=1,2, \cdots n
$$

Where, $x_{i j}$ is non-attribute value of the $j$-th third-level indicators of the $i$-th city, $\overline{x_{j}}$ is the mean value of the $j$-th third-level indicators, $s_{j}$ is the mean variance of the $j$-th third-level indicators, $w_{j}$ is the weight of the $j$-th third-level indicators. The specific calculation results are shown in Table 6 .

Table 6 Measurement index system of sports public service of urban and rural integration

\begin{tabular}{|c|c|c|c|c|c|}
\hline \multirow{3}{*}{ Indicator Type } & \multicolumn{2}{|c|}{ Second-level indicator } & \multicolumn{3}{|c|}{ Third-level indicator } \\
\hline & \multirow{2}{*}{ Elements } & \multirow{2}{*}{ Weights } & \multirow{2}{*}{ Element } & \multicolumn{2}{|r|}{ Weights } \\
\hline & & & & AHP method & Mean variance method \\
\hline \multirow{12}{*}{$\begin{array}{c}\text { Indicator } \\
\text { System Content } \\
\text { A }\end{array}$} & \multirow{4}{*}{ B1 } & \multirow{4}{*}{0.332} & $\mathrm{C} 1$ & 0.1173 & 0.0967 \\
\hline & & & $\mathrm{C} 2$ & 0.1253 & 0.0876 \\
\hline & & & $\mathrm{C} 3$ & 0.1321 & 0.0750 \\
\hline & & & $\mathrm{C} 4$ & 0.1253 & 0.0708 \\
\hline & \multirow{4}{*}{ B2 } & \multirow{4}{*}{0.357} & $\mathrm{C} 7$ & 0.0751 & 0.1094 \\
\hline & & & $\mathrm{C} 8$ & 0.0744 & 0.0854 \\
\hline & & & C9 & 0.0751 & 0.0570 \\
\hline & & & $\mathrm{C} 11$ & 0.0751 & 0.0621 \\
\hline & \multirow{4}{*}{ B3 } & \multirow{4}{*}{0.311} & $\mathrm{C} 12$ & 0.0489 & 0.0970 \\
\hline & & & $\mathrm{C} 13$ & 0.0530 & 0.0820 \\
\hline & & & $\mathrm{C} 14$ & 0.0501 & 0.0765 \\
\hline & & & $\mathrm{C} 15$ & 0.0483 & 0.1005 \\
\hline
\end{tabular}

Demonstration of Measurement Index System of Public Sports Service of Urban-rural Integration. In this paper, the measurement index system of public sports service of urban-rural integration adopted fully absorbed the relevant research results of international and domestic, combined with the suggestions of relevant experts and scholars, using the mean variance decision method and AHP method to determine the index weights, covering the relevant factors in the development process of public sports service of urban-rural integration, the entire structure system can feedback the overall management of urban-rural public sports services.

\section{Conclusions}

The establishment of measurement index system of public sports service of urban-rural integration has a very high reference value for the urban and rural development strategy of China. The AHP method and mean variance decision method are simple and easy, can fully determine the related elements impact on urban and rural public sports service indicators, thus can achieve the long-term dynamic process monitoring of the whole process.

\section{Acknowledgments}

This project was funded by Heilongjiang province philosophy and social science research planning project (16TYD09); Jiamusi University humanities and social sciences project (2014WM21); Jiamusi University 2016 education and teaching research project (2016JW1038). 


\section{References}

[1] Youssef, R.J. Sustainable urban forms, their typologies, models and concepts. Journal of Planning Education and Research. (2006)

[2] Wang Zhang. Towards Urban-rural Integration: The Future of Urban and Rural Masses, Sports Development Strategic Thinking. Journal of Sports and Science, 1 (2010) 52-53.

[3] H.W. Zhang, Connotation Restricting Factors and Development Advice Integration Development of Urban and Rural Sports. Journal of Sports and Science, 6 (2011) 37-41.

[4] B.Q. Luo, F. Zhen, Construction and Application of Evaluation Index System of Integrated Development of Beijing Urban-Rural Sports, China Sport Science, 11 (2010) 24-33.

[5] C. Liu, G. Li, Y.Q. Zhao, A Study on the Problems in the City and Countryside Integration in Public Sports Services and the Counter-measures, Sichuan Sports Science, 3 (2012) 72-75. 